\title{
An option for intraoperative placement of an intra-aortic balloon pump in patients with occlusive peripheral vascular disease
}

\author{
Domenico Calcaterra, MD, PhD, Karam Karam, MD, Jurabek B. Babajanov, MD, and James E. Davis, MD, \\ Iowa City, Iowa
}

\begin{abstract}
Intra-aortic counterpulsation therapy is unanimously recognized as a fundamental tool to support patients with cardiac failure in the preoperative and postoperative periods. The intra-aortic balloon pump (IABP) is routinely inserted through the femoral artery, but in many circumstances this option is not available in patients with occlusive peripheral vascular disease. Access through the upper extremities represents a possible alternative but is often cumbersome and exposed to a high incidence of complications.

We present a technique of intraoperative insertion of the IABP through the innominate artery using a Dacron graft conduit tunneled to the skin above or below the right clavicle.
\end{abstract}

\section{CLINICAL SUMMARY}

The IABP is inserted through a 6-mm Dacron graft sewn to the sidewall of the innominate artery and ultimately tunneled through the soft tissue behind the manubrium. The graft is sewn end-to-side to the takeoff of the innominate artery by using a side-biting clamp. The graft is tunneled behind the manubrium and exited at the skin above or below the right clavicle (Figure 1). The Dacron graft is ligated distally, and the IABP sheath is inserted into the sidewall of the Dacron graft and secured (Figure 2). The IABP can be manipulated and advanced through the innominate artery into the aortic arch. Appropriate positioning in the descending thoracic aorta is completed under transesophageal echocardiographic guidance. The sternotomy is closed, and the IABP insertion site is covered with sterile dressing. Once the patient can be weaned off counterpulsation therapy, the IABP is withdrawn at the bedside. The Dacron graft is ligated and shortened under sterile conditions and ultimately harbored into the skin incision, which can be closed after achievement of local anesthesia.

We used this technique in 2 patients. Both had occlusive iliacofemoral disease, which prevented preoperative completion of coronary artery catheterization from the femoral arteries. Both patients required counterpulsation therapy to

From the Department of Cardiothoracic Surgery, University of Iowa Carver College of Medicine, Iowa City, Iowa.

Disclosures: Authors have nothing to disclose with regard to commercial support.

Received for publication Dec 1, 2009; revisions received May 27, 2010; accepted for publication June 12, 2010; available ahead of print July 15, 2010.

Address for reprints: Domenico Calcaterra, MD, 200 Hawkins Dr SE 517 GH, Iowa City, IA 52242 (E-mail: Domenico-calcaterra@uiowa.edu).

J Thorac Cardiovasc Surg 2011;141:586-7

$0022-5223 / \$ 36.00$

Copyright $@ 2011$ by The American Association for Thoracic Surgery doi: $10.1016 /$ j.jtcvs.2010.06.021
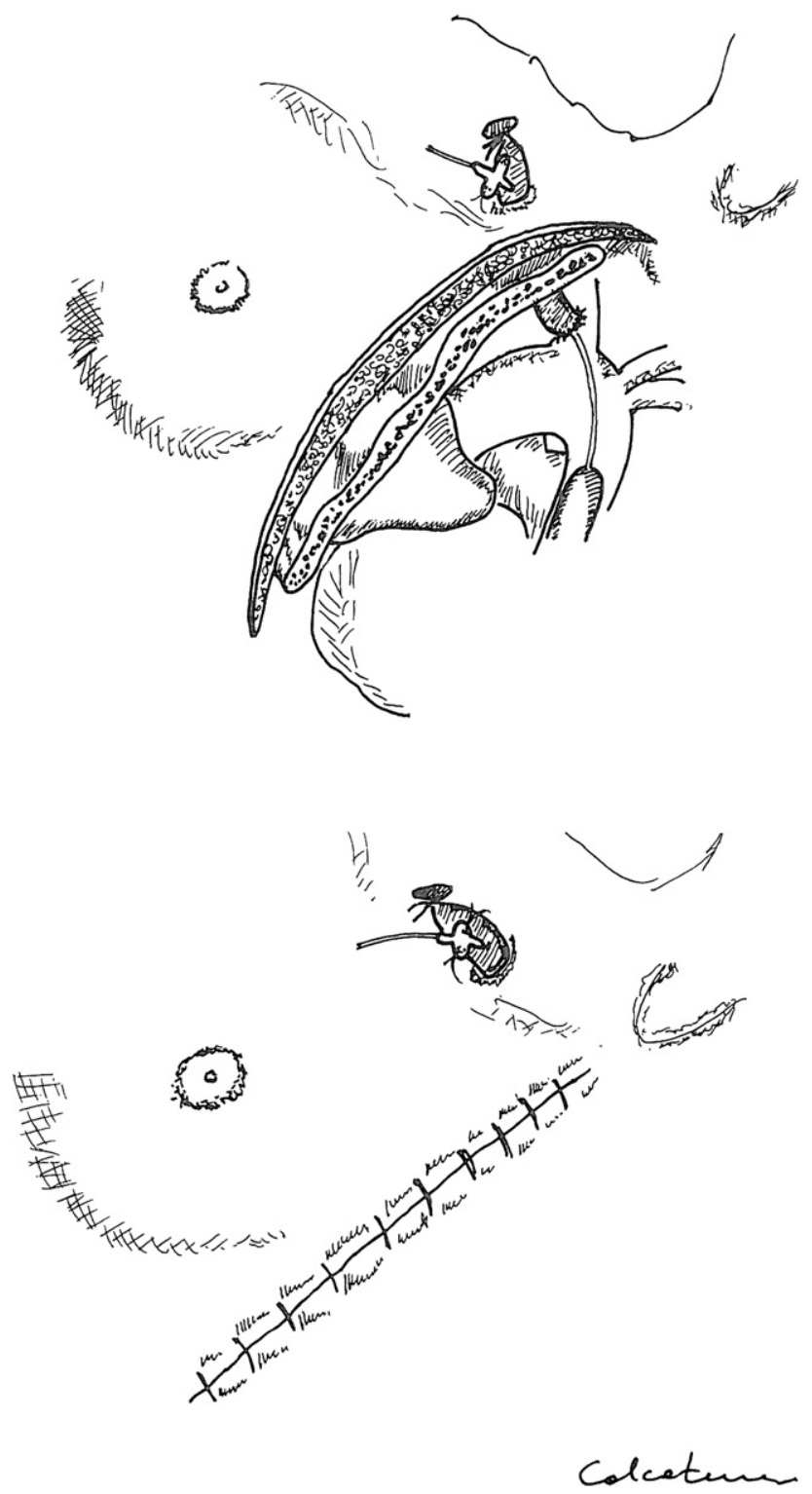

FIGURE 1. The intra-aortic balloon pump is inserted through a 6-mm Dacron graft sewn to the innominate artery and tunneled to the skin behind the right clavicle.

successfully be weaned off cardiopulmonary bypass. One patient died on postoperative day 3 from multiorgan failure caused by low cardiac output state but did not have complications related to the IABP. The second patient had the IABP removed at the bedside on postoperative day 2 . He was extubated successfully and transferred to the floor on 


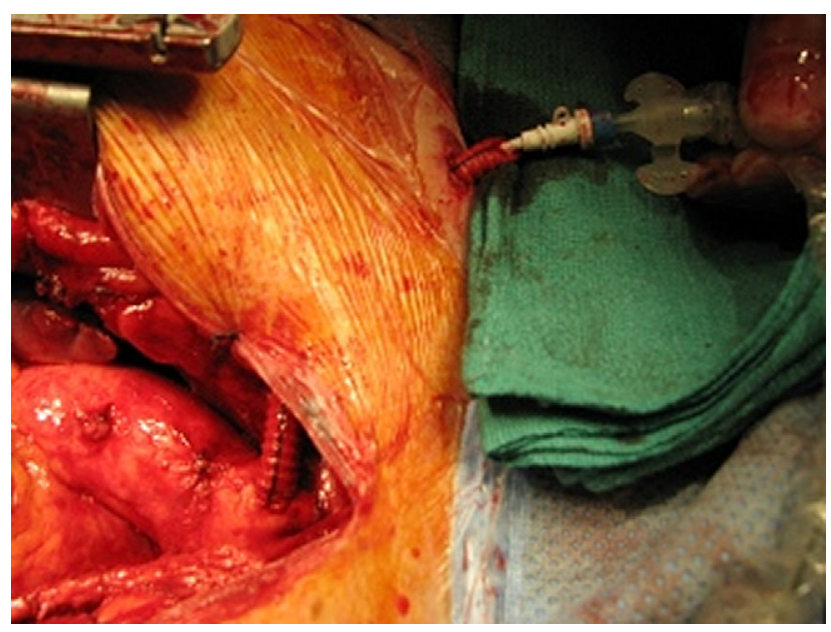

FIGURE 2. Intraoperative image.

postoperative day 4. No complications related to the IABP were encountered.

\section{DISCUSSION}

The IABP acts by increasing diastolic pressure, reducing afterload, increasing coronary artery perfusion, and ultimately increasing stroke volume and cardiac output, with reduction of myocardial oxygen demand. Since its clinical introduction in the early 1970s, the use of intra-aortic counterpulsation therapy in the perioperative period has been shown to decrease mortality in patients with severely decreased ventricular function undergoing cardiac surgery. ${ }^{1,2}$ Intraoperative placement of an IABP might facilitate discontinuation of cardiopulmonary bypass and stabilization of the hemodynamics in patients with poor ventricular function and long pump times. ${ }^{3}$ A technique similar to the one we describe for insertion directly into the aorta of a balloon designed for cannulation into the femoral arteries was described in 1983 by Salerno, ${ }^{4}$ in which the Dacron graft is sewn to the ascending aorta and tunneled behind the sternum below the xyphoid process. Other authors described a similar technique in which the IABP is passed directly through the sternotomy incision. ${ }^{5}$ The advantage of our technique stands in the fact that it might be technically easier and safer to sew the Dacron graft to the innominate artery compared with the ascending aorta already crowded with coronary artery bypass grafts, arterial perfusion, and deairing cannulas. The IABP can be manipulated and guided by means of palpation into the aortic arch. Appropriate positioning in the descending thoracic aorta can be obtained under transesophageal echocardiographic guidance. Alternatively, epiaortic ultrasound can be used to guide the insertion maneuver.

Another advantage is that the Dacron graft runs for a short distance behind the manubrium and does not pass through or behind the sternotomy, as described by other authors. This might result in a decreased risk of deep sternal wound infections. Furthermore, the use of a sheathed balloon introduced through the sidewall of the Dacron graft makes balloon removal easy and safe at the bedside. We acknowledge that this technique might increase the risk of life-threatening complications, such as dissection of the innominate artery, bleeding at the anastomosis site, and brain embolization. In addition, there is increased risk of mediastinal contamination and sternal wound infection. However, we believe that in extreme circumstances in patients with occlusive peripheral vascular disease, it can represent an indispensable tool for discontinuation of cardiopulmonary bypass in the operating room and support of compromised patients in the immediate postoperative period.

\section{References}

1. Ohman EM, George BS, White CJ, Kern MJ, Gurbel PA, Freedman RJ, et al. Use of aortic counterpulsation to improve sustained coronary artery patency during acute myocardial infarction. Results of a randomized trial. The Randomized IABP Study Group. Circulation. 1994;90:792-9.

2. Dietl CA, Berkheimer MD, Woods EL, Gilbert CL, Pharr WF, Benoit CH. Efficacy and cost-effectiveness of preoperative IABP in patients with ejection fraction of 0.25 or less. Ann Thorac Surg. 1996;62:401-9.

3. Macoviak J, Stephenson LW, Edmunds LH Jr, Harken A, MacVaugh H 3rd. The intraaortic baloon pump: an analysis of five years' experience. Ann Thorac Surg. 1980;29:451-8

4. Salerno TA. Insertion of the intra-aortic balloon pump through the ascending aorta and its removal under local anesthesia. Can J Surg. 1983;26:69.

5. Burack JH, Uceda P, Cunningham JN Jr. Transthoracic intraaortic balloon pump: a simplified technique. Ann Thorac Surg. 1996;62:299-301. 